information useful to decision-makers, participation in agenda-setting by stakeholders and communication to the public in general. In fields as diverse as hurricane research and nanomedicine, the contributors demonstrate how initial ambitions to target these values get lost as projects unfold. Too often, the pull of the heavyweight 'science for its own sake' and economic agendas crushes wider intentions.

Policy-makers, funders and scientists should take note. For example, a paper by Ryan Meyer, also a policy scientist at Arizona State University, focuses on the failure of the US government's Global Change Research Program to deliver broad public value (Minerva 49, 47-70; 2011). Basing his studies on public statements and private interviews with researchers and political decision-makers, Meyer says that US climate programmes have in the past two decades benefited from public investment of more than US $\$ 30$ billion, but have largely failed to produce information and participation in the forms that policymakers and the public wanted. The notion that society considers any advance in knowledge to be inherently good - even if the science fails to meet the objectives and priorities it was meant to address - cannot be sustained, says Meyer.

Coincidentally, at a workshop last week in Hamburg, Germany, a gathering of climate scientists, policy experts and philosophers of 'post-normal science' articulated a similar perspective. Science becomes 'post-normal' when facts are uncertain, stakes high, values in dispute and decisions urgent; in such cases, societal needs must be taken into account to avoid costly mistakes. Climate research certainly fulfils this definition. But, according to the workshop participants, most climate researchers continue to act as if purely scientific values are, and will always be, adequate to set the agenda.

Instead, researchers and, especially, their funders must embrace the idea that public and stakeholder participation can help to define research priorities. And they must do more to track and communicate all outcomes. Policy-makers need to ensure that those with direct needs for climate-related information - businesses, regional planners, government departments - have a greater say in the kind of services and knowledge that they expect publicly funded researchers to produce, and in assuring the quality and relevance of what is delivered.

The agenda here is to broaden rather than restrict climate research: to ensure that, alongside studies driven by the priorities of creative scientific imaginations, research also enhances public confidence in society's use of science. A fuller consideration of these issues will also maximize science's public value, in the form of successful collaboration across
"The notion that society considers any advance in knowledge to beinherently good cannot be sustained." disciplinary boundaries, delivery of information useful to stakeholders, and transparency and well targeted communication.

Grant-giving agencies need to take a fresh look at how to address these issues. Lay representation in decision-making, as has already been tried on a limited scale at the US National Institutes of Health, is one way to increase public involvement. Previous exercises in engagement on nanotechnology have led to positive, albeit restricted, outcomes (see Nature 448, 1-2; 2007).

But the problem goes deeper than public engagement. The Global Change Research Program has involved stakeholders at various stages, but, says Meyer, "it is not clear that the US currently has the institutional capacity to achieve the public values promised about climate science". If that is indeed the issue then, given the sheer scale and breadth of US capacity in these topics, one has to wonder whether anyone will be able to achieve what these authors are seeking.

As is often the case, policy researchers are good at identifying problems but slower to reveal how to improve matters. To his credit, Meyer offers some practical ways for the programme to improve the leverage of, and incentives for, a broader participation in delivering public value.

More importantly, these studies highlight a significant deficit in current typical appraisals of science and technology outcomes. They should serve as cautionary tales about the danger of scientists' interests, deliberately or otherwise, becoming too dominant in determining outcomes. And they introduce ways to assess failures in social returns on investment that, one can only hope, will help to improve science's public value.

\section{Online image}

The Internet offers ways for researchers to steer public perceptions, for bad and good.

"M y reputation grows with every failure," said Irish dramatist George Bernard Shaw. And that was before the Internet. Shaw would no doubt be amazed by how quickly electronic bulletin boards such as Facebook and Twitter can now spread the word of deeds both good and bad.

Take the example of Anil Potti, a cancer specialist who resigned his post at Duke University in Durham, North Carolina, last year after it was revealed that he had lied on his CV about being a Rhodes Scholar, and whose research, which had been the basis for clinical cancer trials, was called into question. The Internet should be an unforgiving place for Potti; yet instead of damning news reports, a search on his name throws up a series of plaudits. Numerous websites have been set up to salute his conclusion that smoking causes lung cancer, and to broadcast the information that he enjoys spending time with his family and finished top of his class in high school. Prospective employers who check his background online can still find details of his resignation but will have to look a little bit more carefully.

Job done, then, for Online Reputation Manager, the company listed as an administrative contact in the registration details for two of the more positive sites. Potti is surely grateful for their efforts.

$\mathrm{He}$ is not alone in benefiting from a little electronic-profile polishing. A survey for Nature this week suggests that up to $10 \%$ of scientists have considered using external services to manage their online reputations (see page 138). Others have edited their own biographies on the online resource Wikipedia - a practice that is frowned upon - or inserted references to their own work.

Online reputation is important to most researchers, and about $10 \%$ of respondents to our survey complained that they or their work have been misrepresented on the Internet. The web has a long memory, and rumours, lies and bad information can spiral out of control to be remembered by posterity.

Through responsible use of blogs and social media, researchers have the power to chip away at misperceptions. This isn't about flame wars or trolling comment boards - a lifetime could be spent telling people on the Internet that they're wrong - but rather involves getting the right facts out there, and citing and linking to the best, most trustworthy sources of information.

Such diligence can also benefit scientists as members of a professional community. Researchers who make sure that personal and institutional websites, blogs and social-media pages are accurate and honest will enhance the usefulness of web searches by pushing the most relevant and trusted information to the top. This can make it easier for scientists to find one another for collaboration and reviewing papers, and to locate and fill jobs.

Enhancing visibility and promoting a digital image may strike $\rightarrow$ NATURE.COM To comment online, click on Editorials at: go.nature.com/xhunqv some as unsavoury, but it is not. Researchers are right to promote themselves and their work in a reasonable capacity. The Internet has provided a tremendous tool to do this effectively. And a little more besides. 